\title{
The Association of Menopause and Physical Functioning in Women at Midlife
}

\author{
MaryFran Sowers, PhD, * Sandra Pope, PhD, MPH, ${ }^{+}$Gavin Welch, PhD,* \\ Barbara Sternfeld, $\mathrm{PhD}, \neq$ and Gary Albrecht, $P h D^{\mathbb{S}}$
}

OBJECTIVES: To determine whether the characteristics of menstrual bleeding and the menopausal transition are associated with physical functioning in women age 40 to 55 , after considering ethnicity, ability to pay for basics, body size, and age.

DESIGN: Cross-sectional study.

SETTING: Seven geographically dispersed community samples in the United States.

PARTICIPANTS: The 14,427 respondents were Caucasians $(46.9 \%)$, African Americans $(28.7 \%)$, Chinese $(4.0 \%)$, Japanese $(5.3 \%)$, and Hispanics $(12.6 \%)$ from the Study of Women's Health Across the Nation (SWAN) Cross-sectional Study, a study of the menopausal transition, including surgical menopause.

MEASUREMENTS: The dependent variable was a threecategory variable based on the physical functioning scale of the Medical Outcomes Study. Explanatory variables included menstrual and menopausal status.

RESULTS: Eighty percent $(80.8 \%)$ of women reported no limitation in physical functioning, whereas $10 \%$ of women had some limitation, and $9.2 \%$ of women indicated having substantial limitation. Women with substantial limitation in physical functioning had double the prevalence odds ratio $(\mathrm{POR}=2.02 ; 95 \%$ confidence interval $(\mathrm{CI})=$ 1.64-2.49) of having surgical menopause and $76 \%$ greater odds $(\mathrm{POR}=1.76 ; 95 \% \mathrm{CI}=1.38-2.24)$ ) of using hormones, compared with women with no limitation. Compared with those without limitation, women with substantial limitation in physical functioning had $56 \%$ greater odds $(\mathrm{POR}=1.56 ; 95 \% \mathrm{CI}=1.23-1.97)$ ) of being naturally postmenopausal and a $41 \%$ greater odds (POR $=$ $1.41 ; 95 \% \mathrm{CI}=1.17-1.70$ ) of being perimenopausal, relative to being premenopausal and after adjusting for other variables.

From the "University of Michigan, School of Public Health, Department of Epidemiology, Ann Arbor, Michigan; +UAMS, Women's Outcomes Research, Little Rock, Arkansas; ¥Northern California Kaiser Permanente, Oakland, California; and SUniversity of Illinois at Chicago, Health Policy \& Administration, Chicago, Illinois.

Address correspondence to MaryFran Sowers, PhD, Department of Epidemiology, School of Public Health, University of Michigan, 109 S. Observatory Street, 3073 SPHI, Ann Arbor, MI 48109.
CONCLUSION: Even at the relatively early age of 40 to 55 , approximately $20 \%$ of women self-reported limitation in physical functioning. Surgical menopause and the use of hormones were more frequently observed in women with some and substantial physical limitation than in women with no limitation, even after adjusting for economic status, age, body mass index, and race/ethnicity. J Am Geriatr Soc 49:1485-1492, 2001.

Key words: menopause; functional limitation; women's health; aging

Currently, it is estimated that there are 49 million persons living with physical limitation and disability due to injury, disease, birth defects, and the aging process. ${ }^{1}$ Physical functional limitation is operationally defined in terms of the degree of difficulty in performing activities of daily living such as walking, moving up and down stairs, stooping, bending, lifting a weight, hearing, speaking, eating, maintaining cleanliness, or toileting. ${ }^{2}$ Much of the information about the impact of functional limitation is in relation to healthcare utilization, morbidity, or mortality

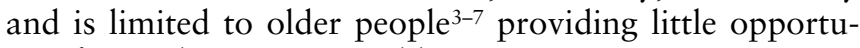
nity for studying its natural history.

The National Health Interview Survey, ${ }^{8}$ using a national, population-based sample, identified through interviews that $15 \%$ of the population between the ages of 45 and 64 had self-reported, severe functional limitations. National data also suggest that of those with functional limitation, $50 \%$ reported that the onset of the limitation became evident between the ages of 40 and 55 .

Women more frequently self-report functional limitation than men. ${ }^{9-12}$ Indeed, even at relatively young ages (40-55), more women report physical limitations and disabilities than do men. ${ }^{13}$ The reason for the greater prevalence of functional limitation in women (who simultaneously have a greater life expectancy) is poorly understood. Recent studies suggests that men and women generally report their disability accurately ${ }^{14}$ and reproducibly ${ }^{15}$ and that the observed higher prevalence of functional problems in women is probably a true reflection of disability. ${ }^{14}$ Thus, factors unique to women must be considered in relation to the increased prevalence of functional limitations in women. 
It is unknown whether factors associated with the menopausal transition ultimately contribute to the excess presentation of functional limitations in older women as compared with older men. The menopausal transition period is an ill-defined period of time, probably lasting 4 to 10 years in which there are known biological changes, including changes in hormone levels, and psychosocial changes, including alteration in social roles. In Figure 1, we have formulated a working model to consider the natural history of functional limitations and how the constructions of the menopausal transition may ultimately influence the development of functional limitations and disability. Briefly, it is hypothesized that there are a number of physiological changes that take place in this transitional period that may predispose women to the development of functional limitations. Some of these hypothesized changes include an increasingly greater fat mass relative to lean mass, an increased likelihood of auto-immune response, a greater likelihood of impaired carbohydrate metabolism, a less favorable lipid profile, and a decline in sensory functions, including vision and hearing. ${ }^{16}$ Whether the menopausal transition or other factors associated with aging enhance these changes is a primary question of the Study of Women's Health Across the Nation (SWAN) study that gave rise to this report. Although there is speculation as to the potential role of the menopausal transition in relation to physical functioning, there have been no systematic evaluations of the concept.

We evaluated the physical functioning Medical Outcome Study-Short Form 36 (MOS-SF-36) of 14,427 women, age 40 to 55 , in relation to five categories in the menopausal transition that includes the use of reproductive hormones. We considered the degree to which self-reported race/ ethnicity, education, age, age at menopause, body mass index (BMI), difficulty in paying for basics, marital status, and employment status were associated with physical functioning and might act as confounding variables in the association of menopausal status with physical functioning.

\section{MATERIALS AND METHODS}

\section{Study Participants}

Participants are women enrolled in the SWAN, a prospective, multicenter, multiethnic, multidisciplinary study of the natural history of the menopausal transition. ${ }^{17}$ SWAN sampling and recruiting was implemented at seven U.S. locations to identify community-based samples of AfricanAmerican (Boston, Chicago, Detroit area, Pittsburgh), nonHispanic Caucasian (all centers), Chinese (Oakland), His-

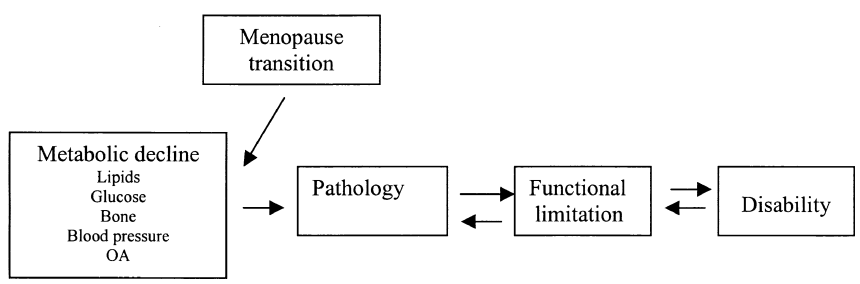

Figure 1. A proposed model of the natural history of physical functioning and the potential role for menopause, based on an extension of the Nagi model (1976). panic (Newark), and Japanese (Los Angeles) women. The study designs consist of a cross-sectional study and subsequent longitudinal study, both of which employ common protocols across the seven study centers.

The two purposes of the SWAN Cross-sectional Study were to identify women eligible for study longitudinally and to assess, cross-sectionally, those factors associated with the age at natural menopause, the prevalence of surgical menopause, symptoms of menopause, health status, and health care use. To be eligible for participation in SWAN Cross-sectional Study, women had to meet the following criteria: (1) primary residence in designated geographic area; (2) the ability to speak English, Spanish, Cantonese, or Japanese; (3) age 40 to 55 ; (4) ability to provide verbal informed consent; and (5) membership in a specific center's targeted ethnic groups. The SWAN Crosssectional Study consisted of a 15- to 20-minute interview administered to 16,065 women.

\section{Study Variables}

\section{Physical Functioning}

The dependent variable was a three-category variable using information from the physical functioning scale of the MOS-SF-36. An interviewer first asked the women, in the language of their preference, if they were "limited in any way in activities because of any impairments or health problems." If there was a negative response, the MOSSF36 physical functioning scale was not administered. Women who gave a positive response $(19.2 \%$ of 16,065$)$ were administered the physical functioning scale, a scale that has been validated in diverse ethnic groups and age ranges. ${ }^{18-21}$ The scale reflects the difficulty of undertaking 10 physical activities that range from vigorous athletic activities to the ability to bathe and dress. The responses were scored using norm-based methods and transformed to have a mean of 50 (standard deviation $=10$ ) in the general U.S. population. The scale and the percentage of women responding to each category are shown in Table 1. Ten percent of the total sample had a score between 50 and 100 and were classified as having some physical limitation, whereas $9.2 \%$ of the total sample had a score between 1 and 50 and were classified as having substantial limitation in their physical functioning.

\section{Menopausal Status}

Menstrual status was defined with a five-category variable based on information from questions about frequency of menstrual bleeding, surgical menopause, and hormone use. The categories and percentage of women in each category were as follows: premenopausal $(32 \%)$, perimenopausal, defined as a menstrual period in the last year but not the last 3 months or a menstrual period in the last 3 months and time between periods becoming more unpredictable $(30 \%)$, naturally postmenopausal and not using hormones $(13 \%)$, surgically postmenopausal and not using hormones $(14 \%)$, and using hormones in the 3 months before interview $(11 \%)$. This last category included women whose commonality was the use of hormones at time of interview but whose postmenopausal status could have arisen naturally or as a result of surgery. 
Table 1. The Percentage of Women, Age 40 to 55, Responding to Individual Items of the Physical Functioning Scale of the Medical Outcomes Study Short Form* and Classified As Having Some and Substantial Limitation in Physical Functioning

Menopause Status Known (Included In Analysis)

\begin{tabular}{|c|c|c|c|c|c|c|}
\hline \multirow[b]{2}{*}{ Activities } & \multicolumn{3}{|c|}{ Some $(n=1,438)$} & \multicolumn{3}{|c|}{ Substantial $(n=1,327)$} \\
\hline & $\begin{array}{c}\text { Limited } \\
\text { a Lot }\end{array}$ & $\begin{array}{l}\text { Limited } \\
\text { a Little }\end{array}$ & $\begin{array}{l}\text { No Limit } \\
\text { at All }\end{array}$ & $\begin{array}{c}\text { Limited } \\
\text { a Lot }\end{array}$ & $\begin{array}{l}\text { Limited } \\
\text { a Little }\end{array}$ & $\begin{array}{c}\text { No Limit } \\
\text { at All }\end{array}$ \\
\hline Vigorous activities & 49.0 & 40.9 & 10.1 & 88.6 & 10.3 & 1.1 \\
\hline Moderate activities & 7.7 & 30.3 & 62.0 & 50.2 & 39.2 & 10.6 \\
\hline Lifting or carrying groceries & 5.2 & 29.8 & 65.0 & 52.5 & 37.8 & 9.6 \\
\hline Climbing one flight of stairs & 1.8 & 18.0 & 80.2 & 47.2 & 40.9 & 11.9 \\
\hline Climbing several flights of stairs & 13.7 & 38.1 & 48.2 & 84.0 & 13.9 & 2.1 \\
\hline Bending, kneeling, or stooping & 10.9 & 39.8 & 49.3 & 62.0 & 30.3 & 7.7 \\
\hline Walking one block & 0.2 & 5.7 & 94.1 & 33.2 & 44.7 & 22.1 \\
\hline Walking several blocks & 3.6 & 21.1 & 75.2 & 68.5 & 25.8 & 5.7 \\
\hline Walking more than a mile & 17.6 & 27.3 & 55.1 & 86.5 & 11.5 & 2.0 \\
\hline Bathing or dressing yourself & 0.8 & 4.5 & 94.6 & 10.4 & 32.3 & 57.3 \\
\hline
\end{tabular}

"Administered if women reported that they were "limited in any way in activities because of any impairments or health problems."

Although the SWAN Cross-sectional Study included responses from 16,065 women, we excluded approximately $10 \%$ of the sample. Data were excluded from analysis $(\mathrm{n}=1,638)$ for an unknown physical functioning status $(\mathrm{n}=39)$, pregnancy, lactation or amenorrhea due to the use of medications or substantial weight change $(\mathrm{n}=$ $310)$, or missing data $(\mathrm{n}=103)$. Additionally, there were pre- $(\mathrm{n}=585)$ or perimenopausal $(\mathrm{n}=599)$ women who had used hormones in the 3-month period preceding the survey, but there was insufficient information to determine whether this hormone use was related to preventing conception or to addressing menstrual-related irregularities or menopause-related conditions. Therefore, these women were excluded from analysis. The distribution of responses to items of the MOS SF-36 among excluded women was similar to the distribution of responses among women included in this report, as shown in Table 2.

Age at menopause and age at surgical menopause were evaluated as log-transformed, continuous variables. Quetelet index (also known as body mass index) was calculated as wt $(\mathrm{kg}) / \mathrm{ht}^{2}(\mathrm{~m})$, based on self-reported weight and height.

\section{Covariates}

Selected demographic and health characteristics were categorized for the SWAN cross-sectional population of 14,427 women. Race/ethnicity was self-identified according to the following categories: Caucasian $(46.9 \%)$, African American $(28.7 \%)$, Chinese $(4.0 \%)$, Japanese $(5.3 \%)$, and two Hispanic groups (from the Caribbean Islands $(6.5 \%)$ and from Mexico and Central America (6.1\%)). The Hispanic groups were recruited at the Newark, New Jersey, center. There were $2.5 \%$ of the enrollees who provided no selfclassification of race/ethnicity.

Education was defined as less than high school (10.4\%), high school $(26.7 \%)$, post-high school $(31.5 \%)$, college $(16.1 \%)$, and postcollege $(15.3 \%)$. As a measure of economic status, participants were asked to rank their degree of difficulty in paying for basics such as food, housing, and health care on a three-item scale, subsequently referred to as "paying for basics." Responses to the paying for basics item were very hard $(12.2 \%)$, somewhat hard $(33.3 \%)$, and not very hard at all $(54.5 \%)$. Marital status was identified as single $(12.9 \%)$, married or living as married $(62.4 \%)$, and other (including widowed, separated, divorced $(24.7 \%))$. Work status was categorized as being employed more than 35 hours/week (58.9\%), being employed less than 35 hours/week (15.9\%), and not employed $(25.2 \%)$. Perception of health was described with a five-level variable with responses of excellent $(18.5 \%)$, very good $(31.4 \%)$, good $(31.2 \%)$, fair $(15.2 \%)$, or poor $(3.4 \%)$. Because of sparser numbers in the last two cells, the numbers from the fair and poor categories were combined.

\section{Statistical Analyses}

All continuous variables were evaluated for normality, and transformations were used when appropriate. Variables for the age at natural menopause and the age at surgical menopause were log-transformed for data analyses, and the anti-log values for these two variables were reported in Table 3. The continuous variables (age, age at menopause, age at surgical menopause, and BMI) were described according to the three-category limitation variable (no, some, and substantial limitation in physical functioning). Analysis of covariance was used to determine the least square means and standard errors for each of the continuous variables according to the three-category physical functioning variable.

The frequencies of categorical variables, including menopausal status, ethnicity, employment status, economic status, and marital status, were tabulated according to the three-category physical functioning variable, and the ensuing associations were evaluated with a chi-squared test of homogeneity. Associations between limitation in physical functioning and the variables were evaluated using logistic regression with $95 \%$ confidence intervals. Ordinal logistic regression models using the three-level physical function- 
Table 2. Classification of Limitation of Physical Functioning According to the Characteristics of Study of Women's Health Across the Nation Enrollees, Age 40 to 55

\begin{tabular}{|c|c|c|c|c|c|c|c|}
\hline \multirow[b]{2}{*}{ Variables } & \multicolumn{2}{|c|}{$\begin{array}{c}\text { No } \\
\text { Limitation }\end{array}$} & \multicolumn{2}{|c|}{$\begin{array}{c}\text { Some } \\
\text { Limitation }\end{array}$} & \multicolumn{2}{|c|}{$\begin{array}{l}\text { Substantial } \\
\text { Limitation }\end{array}$} & \multirow[b]{2}{*}{$P$-value } \\
\hline & \multicolumn{6}{|c|}{ n (\%) } & \\
\hline Ethnicity & & & & & & & $<.001$ \\
\hline African American & 3,225 & $(78.2)$ & 316 & $(7.7)$ & 582 & $(14.1)$ & \\
\hline Caucasian & 5,406 & $(80.1)$ & 832 & (12.3) & 513 & $(7.6)$ & \\
\hline Chinese American & 505 & (86.8) & 62 & (10.7) & 15 & (2.6) & \\
\hline Hispanic Caribbean & 776 & (82.8) & 57 & $(6.1)$ & 104 & $(11.1)$ & \\
\hline Hispanic non-Caribbean & 786 & (89.6) & 40 & $(4.6)$ & 51 & $(5.8)$ & \\
\hline Japanese American & 647 & (85.5) & 93 & $(12.3)$ & 17 & (2.2) & \\
\hline Menstrual status & & & & & & & $<.001$ \\
\hline Premenopausal & 3,986 & $(85.8)$ & 420 & $(9.0)$ & 238 & $(5.1)$ & \\
\hline Perimenopausal & 3,486 & (81.3) & 431 & $(10.1)$ & 370 & (8.6) & \\
\hline Naturally postmenopausal & 1,441 & $(79.1)$ & 150 & (8.2) & 231 & (12.7) & \\
\hline Surgically postmenopausal & 1,509 & $(74.0)$ & 217 & $(10.6)$ & 312 & (15.3) & \\
\hline $\begin{array}{l}\text { Postmenopausal with hormones } \\
\left.\text { (Other }{ }^{*} n=1,638\right)\end{array}$ & 1,240 & $(75.8)$ & 220 & $(13.4)$ & 176 & $(10.8)$ & \\
\hline Education & & & & & & & $<.001$ \\
\hline$<$ High school & 1,134 & $(76.2)$ & 99 & $(6.7)$ & 255 & $(17.1)$ & \\
\hline High school & 3,057 & (79.6) & 359 & (9.3) & 425 & $(11.1)$ & \\
\hline Post-high school & 3,622 & $(80.0)$ & 463 & $(10.2)$ & 442 & $(9.8)$ & \\
\hline College & 1,978 & (85.5) & 226 & $(9.8)$ & 109 & (4.7) & \\
\hline Post-college & 1,816 & $(82.7)$ & 288 & $(13.1)$ & 91 & $(4.1)$ & \\
\hline \multicolumn{8}{|l|}{ Difficulty in paying for basics } \\
\hline Not hard at all & 6,575 & $(84.1)$ & 813 & $(10.4)$ & 434 & $(5.5)$ & \\
\hline Somewhat hard & 3,849 & (80.5) & 427 & (8.9) & 507 & (10.6) & \\
\hline Very hard & 1,186 & (67.5) & 192 & $(10.9)$ & 380 & (21.6) & \\
\hline Marital status & & & & & & & $<.001$ \\
\hline Single & 3,588 & (76.6) & 491 & $(10.5)$ & 607 & $(13.0)$ & \\
\hline Married & 7,486 & (83.4) & 880 & $(9.8)$ & 612 & $(6.8)$ & \\
\hline Other & 561 & $(77.0)$ & 62 & (8.5) & 106 & $(14.5)$ & \\
\hline Work status & & & & & & & $<.001$ \\
\hline Not employed & 2,414 & $(66.5)$ & 415 & $(11.4)$ & 799 & $(22.0)$ & \\
\hline Employed $<35 \mathrm{hr} /$ week & 1,901 & (83.2) & 268 & $(11.7)$ & 117 & $(5.1)$ & \\
\hline Employed $\geq 35 \mathrm{hr} /$ week & 7,324 & (86.3) & 753 & $(8.9)$ & 411 & (4.8) & \\
\hline Perception of health & & & & & & & $<.001$ \\
\hline Excellent & 2,511 & $(94.0)$ & 132 & $(4.9)$ & 27 & $(1.0)$ & \\
\hline Very good & 4,049 & (89.3) & 374 & (8.2) & 111 & (2.4) & \\
\hline Good & 3,610 & (80.3) & 551 & (12.3) & 334 & (7.4) & \\
\hline Fair/Poor & 1,487 & (54.7) & 379 & (13.9) & 852 & (31.3) & \\
\hline
\end{tabular}

Note: $P$-value indicates a difference in frequency within the categories of a specific variable.

${ }^{\star}$ For example, using oral contraceptives or treated with chemotherapy.

ing variable as the outcome failed to meet the assumptions of proportionality. Therefore, multiple variable logistic regression was used to compare women with some limitation in physical functioning to women with no limitation in physical functioning. A second multiple variable logistic regression model was used to compare women with substantial limitation in physical functioning to women with no limitation in physical functioning. The prevalence odds ratio (POR) was the measure of association derived from the beta coefficients of these logistic regression models. All models included indicator variables for age group, menopause status, and race/ethnicity. A variable to represent the SWAN study sites was also included in all logistic regression models, consistent with SWAN analyses policies. The referent group for the logistic models consisted of pre- menopausal 40- to 43-year-old Caucasian participants recruited at the Boston SWAN site. This site was considered "referent" because the study center name was first in an alphabetical listing of all seven centers. The contribution of second-degree terms describing age group by menopause status interactions was evaluated using likelihood ratio tests. The Hosmer-Lemeshow goodness of fit statistic was used to assess the fit of each of the two models. ${ }^{22}$

\section{RESULTS}

\section{Descriptive Analyses}

In this study, $80.8 \%$ of women, age 40 to 55 years, reported no limitation in their physical functioning, whereas $10 \%$ reported some limitation in their physical function- 
Table 3. Characteristics in Women, Age 40 to 55, According to Categories of Physical Functioning

Level of Physical Functioning

\begin{tabular}{cccc}
\hline No Limitation & Some Limitation & Substantial Limitation & \\
\cline { 1 - 3 } & (mean \pm SE) & & $P$-value \\
\hline $46.86 \pm 0.0399$ & $47.18 \pm 0.1137$ & $48.35 \pm 0.1183$ & $<.0001$ \\
$26.70 \pm 0.0600$ & $27.76 \pm 0.1695$ & $31.80 \pm 0.1772$ & $<.0001$ \\
$47.12 \pm 1.0031$ & $47.11 \pm 1.0095$ & $46.49 \pm 1.0077$ & .2660 \\
$37.05 \pm 1.0052$ & $36.69 \pm 1.0137$ & $35.91 \pm 1.0115$ & .0436 \\
\hline
\end{tabular}

$\mathrm{SE}=$ standard error; $\mathrm{BMI}=$ body mass index

ing and $9.2 \%$ reported having substantial limitation in their physical functioning. Table 1 shows the frequency of responses to individual items of the MOS SF-36 when women were classified as having some and substantial limitation in physical functioning. Less than $1 \%$ of women classified as having some limitation reported that they were limited a lot in walking one block, whereas 33\% of women classified as having substantial limitation reported they were limited a lot in walking one block. More than $50 \%$ of women classified with substantial limitation reported that they were limited a lot in climbing a single flight of stairs, whereas less than $2 \%$ of women with some limitation reported that they were limited a lot in climbing a single flight of stairs. Table 2 summarizes the point prevalence of women in each physical functioning category according to ethnicity, menopause status, education, paying for basics, marital status, and work status. Table 3 shows that women with "substantial" limitation in physical functioning were heavier and slightly older than those women reporting no limitation.

\section{Multiple Variable Analyses}

Separate multiple variable logistic models were fit to explain characteristics of women with "some" limitations compared with no limitation and women with "substantial" limitation compared with no limitation, because the polychotomous logistic regression models failed to meet the proportional odds assumption. The logistic regression models, shown Table 4, included all variables that remained statistically significant following bivariate analyses $(P<.10)$ and that were not highly correlated $\left(r^{2}<.70\right)$ to other variables in the model. Thus, the model building excluded the variables age at menopause, age at surgical menopause, education, work status, and marital status.

Model of Women with Some Limitation in Physical Functioning in Comparison with Women with no Limitation. In a multiple variable logistic regression model (Table 4, Column 1), women with some limitation in physical functioning had 1.5 greater odds of having surgical menopause and 1.6 greater odds of using postmenopausally initiated hormones, with premenopause being the referent menstrual status. With the exception of Japanese women, women reporting some limitation were more likely to be Caucasian than were women reporting no limitation. Furthermore, women classified as having some limitation were more likely (POR $=1.66)$ to be classified as obese (as defined by a BMI >30) than women classified as having no limitation. Women at midlife reporting some limitation in physical functioning had $65 \%$ greater odds $(\mathrm{POR}=$ 1.65 ) of reporting difficulty in paying for basics than did women with no limitation.

Model of Women with "Substantial" Limitation in Physical Functioning in Comparison with Women with no Limitation. In a multiple variable logistic regression model (Table 4, Column 2), women who reported substantial limitation in physical functioning had double the odds $(\mathrm{POR}=2.02)$ of having surgical menopause and $76 \%$ greater odds ( $\mathrm{POR}=1.76$ ) of using postmenopausally initiated hormones, with premenopause being the referent menstrual status. Furthermore, there was more than a $50 \%$ greater likelihood $(\mathrm{POR}=1.56)$ of being naturally postmenopausal and a $40 \%$ greater likelihood (POR = 1.41) of being classified as perimenopausal, compared with premenopause as referent and after adjusting for all other variables including age.

Models with and without the age-menstrual status interaction terms were statistically equivalent for both some and substantial physical limitation.

Women reporting substantial limitation in physical functioning had greater odds of being African American $(\mathrm{POR}=1.22)$ than being Caucasian. In contrast, substantial limitation in physical functioning was significantly less in women who classified their origins as Chinese, Japanese, and Hispanic from Mexico or Central America (POR = $0.47, \mathrm{POR}=0.50$, and $\mathrm{POR}=0.49)$, respectively. The odds of being obese were markedly greater $(\mathrm{POR}=2.71)$ in those women having substantial limitation in physical function. The odds of reporting great difficulty in paying for basics were five times greater in women classified as having substantial limitation $(\mathrm{POR}=5.03)$ than in women classified as having no limitation and after considering all other covariates.

\section{DISCUSSION}

Three findings of this study are noteworthy. First, even at the relatively young age of 40 to 55 , an appreciable number of women (approximately 10\%) could be classified as having substantial limitation in their physical functioning. This classification was based on responses to items such as having substantial difficulty in climbing a flight of stairs, bathing or dressing, or walking one block and not by failure to participate in vigorous activities. Second, two as- 
Table 4. In Comparison with No Limitation in Physical Functioning, the Association of Some (Column 1) or Substantial Limitation in Physical Functioning (Column 2) with Menopause Status (Using the Prevalence Odds Ratio (POR)) After Adjusting for All Other Variables in the Models

\begin{tabular}{|c|c|c|c|c|}
\hline Risk Factor/Level & POR & $95 \% \mathrm{Cl}$ & POR & $95 \% \mathrm{Cl}$ \\
\hline \multicolumn{5}{|l|}{ Menopause status } \\
\hline Premenopausal & 1.00 & & 1.00 & \\
\hline Perimenopausal & 1.14 & $0.98-1.33$ & 1.41 & $1.17-1.70$ \\
\hline Postmenopausal with hormones & 1.59 & $1.29-1.95$ & 1.76 & $1.38-2.24$ \\
\hline \multicolumn{5}{|l|}{ Age grouping } \\
\hline $40-43$ & 1.00 & & 1.00 & \\
\hline $44-47$ & 1.11 & $0.95-1.29$ & 1.23 & $1.02-1.50$ \\
\hline $48-51$ & 0.96 & $0.81-1.14$ & 1.54 & $1.27-1.88$ \\
\hline $52-55$ & 1.04 & $0.85-1.27$ & 2.03 & $1.64-2.52$ \\
\hline Hispanic Caribbean & 0.47 & $0.33-0.66$ & 1.03 & $0.75-1.41$ \\
\hline Hispanic non-Caribbean & 0.33 & $0.22-0.49$ & 0.49 & $0.33-0.73$ \\
\hline Japanese & 0.99 & $0.74-1.31$ & 0.50 & $0.28-0.87$ \\
\hline \multicolumn{5}{|l|}{ Study center } \\
\hline Boston & 1.00 & & 1.00 & \\
\hline Chicago & 0.70 & $0.54-0.92$ & 0.76 & $0.58-0.99$ \\
\hline Detroit area & 0.98 & $0.80-1.20$ & 1.58 & $1.30-1.93$ \\
\hline Los Angeles & 1.08 & $0.85-1.39$ & 0.95 & $0.68-1.33$ \\
\hline Newark & 0.83 & $0.65-1.06$ & 0.91 & $0.68-1.22$ \\
\hline Oakland & 1.57 & $1.21-2.04$ & 1.11 & $0.76-1.63$ \\
\hline Pittsburgh & 0.70 & $0.56-0.87$ & 1.00 & $0.80-1.24$ \\
\hline \multicolumn{5}{|l|}{ Model fit information } \\
\hline c-statistic & 0.63 & & 0.77 & \\
\hline Hosmer-Lemeshow test $P$-value & 0.53 & & 0.66 & \\
\hline
\end{tabular}

$\mathrm{CI}=$ confidence interval

pects of the menopausal transition (having surgical menopause or the use of postmenopausally initiated hormones) were more frequently observed in women who reported limitation in physical functioning than in women who reported no limitation, even after adjusting for covariates. Third, economic factors had an important association with physical limitation and appeared to account for some of the contribution of age and race/ethnicity to limitation in physical functioning. However, it must be noted that these findings are based on a cross-sectional survey, precluding either temporal or causal inferences.

Physical functioning and the potential for functional limitation (physical and social/emotional) are believed to be major factors in women's health and women's utilization of healthcare services. ${ }^{3}$ Earlier studies focussed on functional limitation and their association with healthcare utilization by older people. However, more recent research has attempted to better understand the early predictors of functional limitation ${ }^{23}$ and predictors of change in physical functioning. ${ }^{24}$ In two major studies, female participants have been characterized as having more functional limitation than males, ${ }^{23}$ a greater rate of decline in physical function, and less likelihood of recovery from disability. These studies included women age 51 to $61^{23}$ and $\geq 65 .^{24}$

The prevalence of physical limitation in this study of women is similar to the prevalence of functional limitation reported in women in this approximate age range from national probability studies. ${ }^{8}$ Furthermore, the findings of this study are consistent with those reported by Clark et al., ${ }^{23}$ who identified that onset of mobility difficulty in 
men and women age 51 to 61 was best predicted by female sex, less education, low net worth, lack of private health insurance, obesity, and frequent pain.

Previous studies have not examined the contribution of menopausal transition to physical functioning or functional limitation. In the current analyses, women with either some or substantial limitation in physical functioning were consistently and significantly more likely to have had surgical menopause or to be postmenopausal and using hormones than women without functional limitation.

The SWAN Cross-sectional Study interview did not include questions to ascertain the underlying condition(s) that gave rise to surgical menopause; therefore, we can only speculate that those conditions that contributed to surgical menopause may likewise contribute to more limitation in physical functioning. Future work needs to include longitudinal evaluations and explore the likelihood of fibroids, dysfunctional uterine bleeding, endometriosis, and any surgical sequelae to hysterectomy and oophorectomy as potential contributors to the limitation in physical functioning.

Postmenopausal women using hormones were also at risk for the limitation in physical functioning, even after adjusting for age, body size, and measures of socioeconomic status. Identifying hormone replacement therapy (HRT) in postmenopausal women as a risk for limitation in physical functioning is infrequently reported and appears to be in contrast with most studies that report a lower chronic disease prevalence among users of hormones. ${ }^{25}$ However, these observational studies have been criticized for overestimating the benefits of hormone replacement because of the potential "healthy user bias." 26,27 HRT users tend to be a complex group defined not only by the underlying rationale for HRT use, but also for duration of HRT use, type of HRT, and dose of HRT. There was insufficient time during the interview to ascertain the underlying reason why these postmenopausal women were using hormones. However, HRT users in this population were possibly different from those usually reported. This was a younger population than women enrolled in most studies of HRT, ${ }^{28}$ the population was ethnically more heterogeneous, and they were more likely to have been prescribed estrogen/progestin combinations in contrast to conjugated equine estrogens that were extensively used 2 to 3 decades ago. Thus, the users of HRT in this study may have included those women who felt more debilitated by menopausal symptoms, had already experienced the early presentation of chronic disease, or retained characteristics of those underlying conditions that gave rise to surgical menopause.

This cross-sectional study design cannot address whether women with some limitation in physical functioning will progress to having substantial limitation in physical functioning-or move to a definition of functional limitation. In a study of progression by Clark et al. ${ }^{23}$ using two measures 2 years apart and including men and women age 51 to 61 , recovery from mobility difficulty was predicted by having little baseline difficulty and with the absence of diabetes mellitus, lung disease, and frequent pain. An important question will be to determine the role of menopausal status in any potential progression of physical limitation.
This study has a number of methodological issues. It only addressed the physical aspects of functioning. The brief SWAN Cross-sectional Study did not incorporate other recognized measures of cognitive, emotional, and social functioning. ${ }^{2,29}$ Aspects of these measures are more rigorously addressed in the longitudinal SWAN study. The briefness of the cross-sectional interview also precluded us from obtaining information on intermediate factors such as metabolic factors or chronic conditions such as depression.

The actual physical functioning scale was administered only to those $20 \%$ of women ( $\mathrm{n}=2,765)$ who responded affirmatively to a preliminary question that they were "limited in any way in activities because of any impairments or health problems." It would have been desirable to administer the scale to all women to minimize the opportunity for misclassification. Furthermore, the truncated mode of administration made data analysis more complex. If all enrollees had completed the scale, the data would have been analyzed as continuous data. However, because of different data structure, we analyzed these data using two approaches. In addition to the methodology we reported here, we also considered a two-part approach using multiple variable binomial logistic regression to contrast those with and without the scale and multiple variable regression for those who responded to the scale. The two-part approach provided information consistent with that reported in this reported analysis. Additionally, we incorporated the "excluded" women in a special analysis that included dummy variables from seven menopause groups rather than the five reported here. In these analyses, the two groups that remained statistically significantly associated included those with surgical menopause and the postmenopausal women using hormones.

This research suggests that it is important to study women with limitations in physical functioning during the menopausal transition period. Although many of the reported odds ratios are modest and the processes surrounding functional limitations are complex and multifactorial, given the prevalence of both the outcome and the predictors, even small associations could produce significant morbidity in a large population. More women experience menopause than ever before and this number is likely to continue to grow for some time because of national demographic characteristics.

We generally have little information about the experience, risks, or consequences experienced by women with limitation in physical functioning or functional limitation going through menopause. Little is known of the temporal order of diminished physical functioning and menopausal transition states, particularly in women with varying fiscal resources. We also do not know whether women with physical limitations will have greater difficulty addressing issues of the menopausal transition within the healthcare system. Finally, we do not know whether the nature of the menopausal transition influences the progression of functional limitation. Thus, although geriatrics has identified the importance of functional limitation in older people, little attention has been directed toward understanding the natural history of functional limitation (which may begin for many women in mid-life) and chronic diseases. 


\section{REFERENCES}

1. McNeil JM. Americans with disabilities, 1991-1992. Current Population Reports, Series P70, No. 33. Washington, DC: U.S. Department of Commerce, Bureau of the Census, 1993.

2. Applegate WB, Blass JP, Williams TF. Instruments for the functional assessment of older patients. N Engl J Med 1990;322:1207-1214.

3. Guralnik JM, Fried LP, Salive ME. Disability as a public health outcome in the aging population. Annu Rev Public Health 1996;17:25-46.

4. Idler EL, Kasl SV, Lemke JH. Self-evaluated health and mortality among the elderly in New Haven, Connecticut, and Iowa and Washington counties, Iowa, 1982-1986. Am J Epidemiol 1990;131:91-103.

5. Idler EL, Kasl S. Health perceptions and survival: Do global evaluations of health status really predict mortality? J Gerontol 1991;46:S55-S65.

6. Kaplan GA, Camacho T. Perceived health and mortality: A nine-year followup of the Human Population Laboratory cohort. Am J Epidemiol 1983;117: 292-304.

7. Mossey JM, Shapiro E. Self-rated health: A predictor of mortality among the elderly. Am J Public Health 1982;72:800-808.

8. National Center for Health Statistics. Health, United States, 1996-97 and Injury Chartbook (DHHS Publ. No (PHS) 97-1232). Hyattsville, MD: Department of Health and Human Services, 1997.

9. Maddox GL, Clark DO. Trajectories of functional impairment in later life. J Health Soc Behav 1992;33:114-125.

10. Verbrugge LM. The twain meet: Empirical explanations of sex difference in health and mortality. J Health Soc Behav 1989;30:282-304.

11. Nagi SZ. An epidemiology of disability among adults in the United States. Milbank Memorial Fund Q 1976;54:439-467.

12. Ross CE, Bird CE. Sex stratification and health lifestyle: Consequence for men's and women's perceived health. J Health Soc Behav 1994;355:161-178.

13. Centers for Disease Control and Prevention. 1994. Prevalence of disabilities and associated health conditions-United States, 1991-1992. Mor Mortal Wkly Rep CDC Surveill Summ 1993;43:730.

14. Merrill SS, Seeman T, Kasl SV et al. Gender differences in the comparison of self-reported disability and performance measures. J Gerontol A Biol Sci Med Sci 1997;52A:M19-M26.

15. Rathouz, PJ, Kasper JD, Zeger SL et al. Short-term consistency in self-reported physical functioning among elderly women: The Women's Health and Aging Study. Am J Epidemiol 1998;147:764-773.
16. Sowers MF, La Pietra M. Menopause: Its epidemiology and potential association with chronic diseases. Epid Rev 1995;17:287-302.

17. Sowers MF, Crawford S, Sternfeld B et al. Design, survey sampling and recruitment methods of SWAN: A multi-center, multi-ethnic, community-based cohort study of women and the menopausal transition. In: Wren J, Lobo RA, Kelsey J, et al., eds. Menopause: Biology and Pathobiology. New York: Academic Press, 2000, pp 177-188.

18. Brazier JE, Harper R, Jones NMB et al. Validating the SF-36 health survey questionnaire: New outcome measure for primary care. BMJ 1992;305:160-164.

19. McHorney CA, Ware JE, Raczek AE. The MOS 36-item short form health survey (SF-36): II. Psychometric and clinical tests of validity in measuring physical and mental health constructs. Med Care 1993;31:247-263.

20. McHorney CA, Ware JE, Lu RJF et al. The MOS 36-item short for health survey (SF-36): III. Tests of data quality, scaling, assumption and reliability among diverse patient groups. Med Care 1994;32:40-66.

21. Ware JE, Sherbourne CD. The MOS 36-item short-form health surveys: I. Conceptual framework and item selection. Med Care 1992;30:473-483.

22. Hosmer DW, Lemeshow S. Applied Logistic Regression. New York: Wileym, 1989.

23. Clark DO, Stump TE, Wolinsky FD. Predictors of onset of and recovery from mobility difficulty among adults aged 51-61 years. Am J Epidemiol 1988;148:63-81.

24. Becket LA, Brock DB, Lemke JH, et al. Analysis of change in self-reported physical function among older persons in four population studies. Am J Epidemiol 1996;143:766-778.

25. Grodstein F, Stampfer M. The epidemiology of coronary heart disease and estrogen replacement in post menopausal women. Prog Cardiovasc Dis 1995; 38:199-210.

26. Sturgeon SR, Schairer C, Brinton LA et al. Evidence of a healthy estrogen user survivor effect. Epidemiology 1995;6:227-231.

27. Posthuma WFM, Westendorp RG, Vandenbroucke JP. Cardioprotective effect of hormone replacement therapy in postmenopausal women: Is the evidence biased. BMJ 1994;308:1268-1269.

28. Buist DSM, La Croix AZ, Newton KM et al. Are long-term hormone replacement therapy users different from short-term and never users? Am J Epidemiol 1999;149:275-281.

29. Armenian HK, Pratt LA, Gallo J et al. Psychopathology as a predictor of disability: A population-based study in Baltimore, Maryland. Am J Epidemiol 1998;148:269-275. 